\title{
THE INFLUENCE OF EXPENSE LOADINGS ON THE FAIRNESS OF A TARIFF
}

\author{
By JeAn Lemaire \\ Université Libre de Bruxelles, Brussels, Belgium
}

\begin{abstract}
In non-life insurance, it is nearly always assumed that the expense loading is a fraction of the risk premium. This may deeply affect the fairness of a tariff, as illustrated in the case of the Belgian bonus-malus system.
\end{abstract}

\section{KEYWORDS}

Rate making, Expense loadings.

\section{INTRODUCTION-SUMMARY}

The exponential growth of the number of papers dealing with the theory of premium calculation principles is one of the significant trends of the actuarial science during the last decade. Also noteworthy is the fact that all of those papers concentrate on the risk premium (pure premium and safety loading) and deliberately leave aside the determination of the loading for expenses, commissions, taxes, profit, ... We shall attempt to show in this paper that this neglect has some severe consequences, that it is futile to try to assess the risk premium with great precision if the expense loading is only grossly estimated, that risk premiums with desirable characteristics in terms of the principles of risk classification are distorted through the loading process (this should be obvious since in many cases the expense loading is greater than the risk premium). Note that the same remark was made by JEWELL (1980): "The next step in premium setting is to determine the additional $50-200 \%$ increase which determines the commercial premium by adding expense and profit loadings. Except in life insurance where there are specific cost models for sales commissions (in many cases of regulated form), there seems to be no further modelling principles used, except [multiplying the risk premium by a factor $1+\alpha$ ]. This lacuna in the literature is all the more surprising, as it is in sharp contrast to the fields of engineering and business management, where extensive and sophisticated cost allocation and modelling are the order of the day. Are these activities outside the realm of the actuary,...?"

\section{APPARENT AND REAL RISK PREMIUMS}

In all lines of insurance the policy-holders are partitioned according to some criteria that significantly affect the risk (like use and power of the car, age and occupation of the driver in motorcar insurance). Let $s$ be the number of cells, ASTIN BULLETIN Vol. 14, No. 2 
and $\left\{b_{i} ; i=1, \ldots, s\right\}$ the commercial tariff: $b_{i}$ is the premium to be paid by a policy-holder that belongs to cell $i . b_{i}$ is the sum of two components: the risk premium $r_{i}$ and the expense loading $e_{i}$, that contains the company's general expenses $g_{i}$, the commissions $c_{i}$, the taxes $t_{i}$, and, in some cases, a profit loading $p_{i}$ :

$$
b_{i}=r_{i}+e_{i}, \quad i=1, \ldots, s
$$

where $e_{i}=g_{i}+c_{i}+t_{i}+p_{i}$.

In non-life insurance, it is nearly always assumed* that the expense loading is a fraction of the risk premium:

$$
b_{i}=r_{i}(1+\alpha), \quad \alpha>0, \quad i=1, \ldots, s .
$$

The loading coefficient $\alpha=\alpha_{\mathrm{g}}+\alpha_{\mathrm{c}}+\alpha_{t}+\alpha_{p}$, where

$$
\begin{aligned}
& \alpha_{g}=\text { loading coefficient for general expenses } \\
& \alpha_{c}=\text { loading coefficient for commissions } \\
& \alpha_{t}=\text { loading coefficient for taxes } \\
& \alpha_{p}=\text { loading coefficient for profits. }
\end{aligned}
$$

This proportional approach is certainly open to some criticisms. Why should the salesmen of the company (brokers, agents, ...) be paid more for bad risks than for good risks (on the contrary we feel that they should be rewarded for bringing good risks to the company)? Is it fair that young drivers pay more taxes than older policy-holders? Is there any reason for the fact that drivers living in big cities contribute more to the profit of the company than inhabitants of small communities? If a proportional loading is applied, the high risk cells certainly pay a disproportionate share of the expenses. This means that the "real" risk premium they pay is not $r_{i}$, but $r_{i}^{\prime}=r_{i}+(E X)_{i}$, where $(E X)_{i}$ is the excess charge of expenses (considered here as the "hidden" part of the risk premium).

\section{(a) A Special Case: Flat Expense Loading}

Suppose that there is no reason whatsoever that the high risk cells contribute more towards the expenses than the low risks, and denote by $n_{i}$ the population of cell $i$. Instead of paying $b_{i}=r_{i}(1+\alpha)$, a risk that belongs to cell $i$ should pay

\footnotetext{
* Among the few exceptions we found in the literature were

- the proposed new motor rating structure in the Netherlands; the authors' recommended rates are applicable for $90 \%$ of the premium income (including the part of the component for expenses contained therein), while the remaining $10 \%$ is considered to relate to expenses which should be appropriated towards each policy as a fixed amount (GREGORIUS (1982)):

- a recommendation of the Massachusetts Insurance Service Office (RoY (1980)). The proposition is to allocate $75 \%$ of the operating costs as a fixed amount, and the remaining $25 \%$ as a proportional loading.
} 
$b_{i}^{\prime}=r_{i}+\beta$, where

$$
\begin{aligned}
\beta & =\frac{1}{n}\left(\alpha \sum_{i=1}^{s} n_{i} r_{i}\right) \\
& =\frac{\alpha}{1+\alpha} \frac{\sum_{i=1}^{s} n_{i} b_{i}}{n}
\end{aligned}
$$

is computed in such a way that the total income $\sum_{i} n_{i} b_{i}$ of the company is not modified. As this risk effectively pays $b_{i}$, he is charged a (positive or negative) excess premium of

$$
\begin{aligned}
(E X)_{i} & =\alpha r_{i}-\beta \\
& =\frac{\alpha}{1+\alpha}\left[b_{i}-\frac{\sum_{i} b_{i} n_{i}}{n}\right] .
\end{aligned}
$$

The real risk premium paid is thus

$$
r_{i}^{\prime}=r_{i}+(E X)_{i}=b_{i}-\beta
$$

(b) A More General Case: Linear Loading

Suppose now that the expense loading should be partly proportional to the risk premium, partly uniform. Instead of being charged $b_{i}=r_{i}(1+\alpha)$, a risk of cell $i$ should contribute

$$
b_{i}^{\prime}=r_{i}(1+\gamma)+\beta,
$$

where $\gamma=\gamma_{g}+\gamma_{c}+\gamma_{t}+\gamma_{p}$, and $\beta=\beta_{g}+\beta_{c}+\beta_{t}+\beta_{p}$.

The total proportional part of the company's income is

$$
(1+\gamma) \sum_{i} n_{i} r_{i}=\frac{1+\gamma}{1+\alpha} \sum_{i} n_{i} b_{i}
$$

In order to keep the same total income, $\beta$ should then be equal to

$$
\begin{aligned}
\beta & =\frac{1}{n}\left(\sum_{i} n_{i} b_{i}-\frac{1+\gamma}{1+\alpha} \sum_{i} n_{i} b_{i}\right) \\
& =\frac{\alpha-\gamma}{1+\alpha} \frac{\sum_{i} n_{i} b_{i}}{n} .
\end{aligned}
$$

The excess premium for cell $i$

$$
\begin{aligned}
(E X)_{i} & =\alpha r_{i}-\left(\gamma r_{i}+\beta\right) \\
& =\frac{\alpha-\gamma}{1+\alpha}\left[b_{i}-\frac{\sum_{i} n_{i} b_{i}}{n}\right] .
\end{aligned}
$$


Then the real risk premium is

$$
r_{i}^{\prime}=r_{i}+(E X)_{i}=\frac{1}{1+\alpha}\left[b_{i}(1+\alpha-\gamma)-(\alpha-\gamma) \frac{\sum_{i} n_{i} b_{i}}{n}\right] .
$$

Of course other expense allocation models are conceivable (commissions designed in such a way that the broker has an incentive to sign up good risks, for instance), but the model considered in (b) is more likely to be selected in practice, due to its simplicity.

\section{AN 'APPLICATION}

Since 1971, all Belgian companies are compelled to use an 18-class merit-rating system in motorcar third-party insurance. The premium levels $\left\{b_{i} ; i=1, \ldots, 18\right\}$ are presented in Table 1 along with the populations $n_{i}$ observed in a company (columns 1 and 2 ). The expense loading is purely proportional, with the following coefficients

Company expenses

Commissions

Taxes $\left\{\begin{array}{l}\text { for the social security system } \\ \text { for the fund of the handicapped } \\ \text { for the Red Cross } \\ \operatorname{tax}\end{array}\right.$

$$
\left.\begin{array}{lr} 
& \begin{array}{r}
\alpha_{g}=0.5901 \\
\alpha_{c}=0.3257
\end{array} \\
\alpha=0.1916 \\
\alpha=0.1149 \\
\alpha=0.0048 \\
\alpha=0.1722
\end{array}\right\} \begin{array}{r}
\alpha_{t}=0.4885 \\
\text { oading } \quad \alpha=1.4043
\end{array}
$$

The expense loading thus multiplies the risk premium by 2.4 !

\section{(a) Flat Expense Loading}

Let us assume that the fair way to allocate expenses is that each policy-holder pays a fixed amount. In our example we obtain

$$
\beta=\frac{\alpha}{1+\alpha} \frac{\sum_{i} n_{i} b_{i}}{n}=39.9308 .
$$

We then compute the excess premium, and express it as a percentage of the commercial premium $b_{i}$ (see Table 1 , columns 3 and 4). For instance a policyholder of class 18 can claim that he is being overcharged by 76.88 , or $38.44 \%$ ! Then, we substract $\beta$ from $b_{i}$ in order to obtain the real risk premium (column 5 ). By multiplying the figures of this column by 1.6647 (in order to bring back the premium of the initial class 10 to 100 ), we obtain the "real" merit-rating system applied by the Belgian companies. It differs markedly from the "alleged" one: for instance the ratio between the largest and smallest premiums is 8 , instead of the apparent 3.33 ! 
TABLE 1

FLAT EXPENSE LOADING

\begin{tabular}{|c|c|c|c|c|c|}
\hline$b_{i}$ & $n_{i}$ & $(E X)_{i}$ & $\frac{(E X)_{i} \times 100}{b_{i}}$ & $r_{i}^{\prime}$ & "Real" System \\
\hline 200 & 27 & 76.88 & 38.44 & 160.0692 & 266.47 \\
\hline 160 & 28 & 53.52 & 33.45 & 120.0692 & 199.88 \\
\hline 140 & 53 & 41.83 & 29.88 & 100.0692 & 166.59 \\
\hline 130 & 81 & 36 & 27.69 & 90.0692 & 149.94 \\
\hline 120 & 115 & 30.16 & 25.13 & 80.0692 & 133.29 \\
\hline 115 & 201 & 27.24 & 23.69 & 75.0692 & 124.97 \\
\hline 110 & 322 & 24.32 & 22.11 & 70.0692 & 116.65 \\
\hline 105 & 507 & 21.40 & 20.38 & 65.0692 & 108.32 \\
\hline 100 & 1141 & 18.48 & 18.48 & 60.0692 & 100 \\
\hline 100 & 1429 & 18.48 & 18.48 & 60.0692 & 100 \\
\hline 95 & 2318 & 15.56 & 16.37 & 55.0692 & 91.68 \\
\hline 90 & 3385 & 12.64 & 14.04 & 50.0692 & 83.35 \\
\hline 85 & 9190 & 9.72 & 11.43 & 45.0692 & 75.03 \\
\hline 80 & 9791 & 6.79 & 8.49 & 40.0692 & 66.71 \\
\hline 75 & 9887 & 3.87 & 5.17 & 35.0692 & 58.38 \\
\hline 70 & 12231 & 0.95 & 1.36 & 30.0692 & 50.06 \\
\hline 65 & 11025 & -1.95 & -3.02 & 25.0692 & 41.73 \\
\hline \multirow[t]{2}{*}{60} & 70962 & -4.89 & -8.14 & 20.0692 & 33.41 \\
\hline & 132693 & & & & \\
\hline
\end{tabular}

(b) Linear Loading

To be more realistic, let us compute the real "hidden" merit-rating system under the following assumptions.

(i) Commissions should be the same for every risk.

Indeed in Belgium a broker is nothing more than a salesman, and does not participate in the settlement of claims. He should not have any incentive to sign up customers that belong to the worst risk classes. So $\gamma_{\mathrm{c}}=0$ and

$$
\beta_{\mathrm{c}}=\alpha_{\mathrm{c}} \frac{\sum_{i} n_{i} r_{i}}{n}=\frac{\alpha_{\mathrm{c}}}{1+\alpha} \frac{\sum_{i} n_{i} b_{i}}{n}=9.2608 .
$$

(ii) The contributions to the social security system, the fund of the handicapped and the Red Cross should be proportional to the risk premium.

Bad risks have a higher propensity to cause claims with bodily injury, thereby adding their share to the deficits of the social security system and the fund of the handicapped. It is only fair that they should pay for it. So $\gamma_{t}=0.3113$.

(iii) The tax should be the same for all policy-holders. So

$$
\beta_{t}=\frac{\alpha_{t}-\gamma_{t}}{1+\alpha} \frac{\sum_{i} n_{i} b_{i}}{n}=5.0390 .
$$


(iv) The part of the general expenses related to the production and the administration of the policies should be uniformly distributed among the policyholders. The part related to the claims settlement should be proportional to the risk premium. In a large Belgian company, the former part accounts for $72.54 \%$ of the general expenses, the latter part for the remaining $27.46 \%$. This leads to $\gamma_{g}=0.1620$ and

$$
\beta_{g}=\frac{\alpha_{g}-\gamma_{g}}{1+\alpha} \frac{\sum_{i} n_{i} b_{i}}{n}=12.1714
$$

Assembling the three components, we have

$$
\begin{aligned}
& \gamma=\gamma_{c}+\gamma_{t}+\gamma_{g}=0.4733 \\
& \beta=\beta_{c}+\beta_{t}+\beta_{g}=26.4712
\end{aligned}
$$

Altogether, around one third of the total expense loading is allocated proportionally, the remaining two thirds evenly.

The computations described in Section 2 enable us to compute the "real" merit-rating system applied by the Belgian companies; it is more severe than the "official" one, since for instance the ratio between the extreme premiums is 6.18 , instead of the apparent 3.33.

It was stated over and over again [see for instance LEMAIRE (1982)] that the Belgian bonus-malus system is unefficient and unfair to the best drivers, since the penalizations for claims are much too small.

The preceding considerations show that the effect of a purely proportional loading is to attenuate this unfairness.

\begin{tabular}{|c|c|c|c|c|}
\hline$b_{i}$ & $(E X)_{i}$ & $\frac{100(E X)_{i}}{b_{i}}$ & $r_{i}^{\prime}$ & "Real" System \\
\hline 200 & 50.97 & 25.48 & 134.15 & 249.16 \\
\hline 160 & 35.48 & 22.18 & 102.03 & 189.50 \\
\hline 140 & 27.74 & 19.81 & 85.97 & 159.67 \\
\hline 130 & 23.86 & 18.36 & 77.94 & 144.75 \\
\hline 120 & 19.99 & 16.66 & 69.90 & 129.83 \\
\hline 115 & 18.06 & 15.70 & 65.89 & 122.37 \\
\hline 110 & 16.12 & 14.65 & 61.87 & 114.92 \\
\hline 105 & 14.18 & 13.51 & 57.86 & 107.46 \\
\hline 100 & 12.25 & 12.25 & 53.84 & 100 \\
\hline 100 & 12.25 & 12.25 & 53.84 & 100 \\
\hline 95 & 10.31 & 10.86 & 49.83 & 92.54 \\
\hline 90 & 8.38 & 9.31 & 45.81 & 85.08 \\
\hline 85 & 6.44 & 7.58 & 41.79 & 77.63 \\
\hline 80 & 4.50 & 5.63 & 37.78 & 70.17 \\
\hline 75 & 2.57 & 3.42 & 33.76 & 62.71 \\
\hline 70 & 0.63 & 0.90 & 29.75 & 55.26 \\
\hline 65 & -1.30 & -2.01 & 25.73 & 47.79 \\
\hline 60 & -3.24 & -5.40 & 21.72 & 40.33 \\
\hline
\end{tabular}

TABLE 2

LINEAR LOADING 


\section{REFERENCES}

Gregorius, F. (1982) Development of the Study. In New Motor Rating Structure in the Netherlands. ASTIN-Groep Nederland, pp. 15-37.

Jewell, W. (1980) Models in Insurance: Paradigms, Puzzles, Communications and Revolutions. Proc. of the 2/st I.C.A. Zürich-Lausanne.

Lemaire, J. (1982) L'assurance Automobile: Modèles Mathématiques et Statistiques. Fernand NathanEditions Labor.

RoY, J. (1980) La Tarification en Assurance Automobile au Québec. Rapport du Surintendạnt des Assurances. 